\title{
GSTM1 null genotype, red meat consumption and breast cancer risk (The Netherlands)
}

\author{
Olga L. van der $\mathrm{Hel}^{1,3, \dagger}$, Petra H.M. Peeters ${ }^{1, *}$, David W. Hein ${ }^{2}$, Mark A. Doll ${ }^{2}$, Diederick E. Grobbee ${ }^{1}$, Marga \\ Ocké $^{3} \&$ H. Bas Bueno de Mesquita ${ }^{3}$ \\ ${ }^{1}$ Julius Center for Health Sciences and Primary Care, University Medical Center, Utrecht, P.O. Box 85500, 3508 GA \\ Utrecht, The Netherlands; ${ }^{2}$ Department of Pharmacology and Toxicology, University of Louisville, School of \\ Medicine, Louisville, Kentucky 40292, USA; ${ }^{3}$ Department of Chronic Diseases Epidemiology, National Institute of \\ Public Health and the Environment, P.O. Box 1, 3720 BA Bilthoven, The Netherlands \\ ${ }^{\dagger}$ Current address: Unit of Environmental Cancer Epidemiology, International Agency for Research on Cancer, Lyon, \\ France
}

Received 22 May 2003; accepted in revised form 29 January 2004

Key words: breast cancer, glutathione- $S$-transferase, meat, $N$-acetyltransferase, nested case-control.

\begin{abstract}
Objective: We studied whether polymorphisms in $N$-acetyltransferase 1 and 2 and Glutathione $S$-transferase M1 and $\mathrm{T} 1$ genes modify the association between meat consumption and breast cancer.

Methods: A nested case control was conducted in a Dutch prospective cohort. Breast cancer cases (229) and controls (264) were frequency matched on age, town and menopausal status.

Results: There is no relation between any type of meat consumption (i.e., total meat, processed meat, fresh meat, red meat and white meat) and breast cancer risk. Neither presence of $N A T 1$ or $N A T 2$ rapid genotype, or GSTT1 null genotype, alone or in combination with meat consumption affects breast cancer risk. Absence of GSTM1 shows $46 \%$ increased breast cancer risk $(\mathrm{OR}=1.46(95 \%$ confidence interval, $95 \% \mathrm{CI}=1.02-2.09))$. When stratifying according to combined 'GSTM1 genotype-meat consumption' categories, breast cancer risk is slightly increased with consumption of red meat both in women with genotype GSTM1 presence (OR $=1.49$ and 1.75 for intermediate and high versus low consumption) and in GSTM1 null genotype $(\mathrm{OR}=1.18$ and 1.02). These increases are statistically not significant. In postmenopausal women a suggestion of an effect of red meat consumption is observed: effects are slightly stronger, although still not statistically significant and without a clear dose-response relation: $\mathrm{OR}=1.79(95 \% \mathrm{CI}=0.92-3.50)$ and $1.46(1.46(95 \% \mathrm{CI}=0.76-2.82)$ for intermediate and high compared to low red meat consumption respectively. Reliable evaluation of interaction is not possible due to the small number of cancers.

Conclusion: GSTM1 null genotype increases breast cancer risk. Red meat consumption slightly increases breast cancer risk, but the relation is not statistically significant and GSTM1, NAT1, NAT2 and GSTT1 polymorphisms do not modify this relation.
\end{abstract}

\section{Introduction}

It is assumed that breast cancer is caused by both environmental and genetic factors. The role of environ-

\footnotetext{
* Address correspondence to: Petra H.M. Peeters, Julius Center for Health Sciences and Primary Care, HP: D01.335, University Medical Center Utrecht, P.O. Box 85500, 3508 GA Utrecht, The Netherlands. Ph.: +31-30-2509363; Fax: +31-30-2505480/5484; E-mail: p.h.m. peeters@jc.azu.nl
}

mental carcinogen exposure, e.g. dietary components, in particular meat consumption, has not been well defined. A recent pooled analysis of eight prospective cohort studies did not find an association between intake of total meat, red meat or white meat [1]. However, if meat plays a role in the etiology of breast cancer this could be through the formation of mutagens and/or carcinogens, such as heterocyclic amines (HA), during high temperature cooking of meat [2]. Consumption of well-done 
meat has been associated with an increased human breast cancer risk in some but not all epidemiological studies [3-6].

2-amino-1-methyl-6-phenylimidazo[4,5-b] pyridine (PhIP) is the most abundant and carcinogenic HA in grilled meat and therefore a role for this compound is strongly implied [7]. In vitro studies have now shown that PhIP is metabolically activated and forms DNA adducts in human mammary epithelial cells [8]. A recent study showed that PhIP and benzo $[a]$ pyrene $(\mathrm{B}[a] \mathrm{P})$ bind to human breast DNA after administration of a defined low dose [9] and another study indicated that carcinogens, among others HA, react with DNA in human breast ductal epithelial cells [10].

After activation, HA are either detoxified or activated to more potent carcinogens by $N$-acetyltransferases (NAT1 and NAT2) [11]. Several polymorphisms are known in the NAT1 and NAT2 genes, which result phenotypically in individuals who are slow or rapid acetylators [12]. Due to differences in enzyme activity, polymorphisms in genes of metabolizing enzymes may increase breast cancer risk in women who are exposed to carcinogens from meat intake. Results on meat consumption, metabolic polymorphisms and their role in breast cancer are conflicting [13-19].

Moreover, these studies focussed on $N$-acetyltransferases, while the carcinogens may be detoxified by glutathione $\mathrm{S}$ transferases as well (GST $\mu 1$ and GST $\theta 1)$ $[20,21]$. Enzyme activity of GST $\mu 1$ or GST $\theta 1$ can also vary between individuals because of an inherited deletion of GSTM1 or GSTT1 gene, resulting in the null genotype [22].

The aim of the present study was to investigate the relation between meat intake, polymorphisms in all the genes, (NAT1, NAT2, GSTM1, GSTT1), and breast cancer risk in a nested case-control study.

\section{Materials and methods}

\section{Study population}

We conducted a nested case-control study using subjects enrolled in the Monitoring Project on Cardiovascular Disease Risk Factors conducted in three Dutch towns, i.e. Amsterdam, Maastricht and Doetinchem, between January 1987 and December 1991. More than 36,000 men and women were enrolled. A detailed description of this project was published previously [23]. In brief, each year, a random sample of men and women, aged 2059 years, was selected from the municipal registries of the three towns and invited to participate. The overall response rate was $50 \%$ for men and $57 \%$ for women.
The Medical Ethical Committee of the University of Leiden, The Netherlands, approved the study protocol.

In Doetinchem, some subjects participated more than once and duplicate observations from these participants ( $\mathrm{n}=1097$; first record was used) were excluded. We further excluded subjects who could not be identified in the National Population Database $(n=24)$, whose vital status by December, 311997 was unknown $(\mathrm{n}=343)$, who disagreed with the release of medical records from their general practitioner and were therefore not submitted for linkage to the cancer registry $(n=597)$, did not provide a blood sample $(n=705)$, were of presumed non-Caucasian ethnicity $(n=1402)$, or had cancer previous to their inclusion into the cohort (except nonmelanoma skin cancer and cervix cancer in situ or lobular breast cancer in situ $(\mathrm{n}=542))$. From the resulting cohort, we included all first incident breast cancer cases and a random sample from the controls as described below.

Follow-up for incident cancer from 1987 to 1997 was achieved via computerized record linkage with the Netherlands Cancer Registry (NCR) and with the three regional cancer registries (IKA, IKL and IKO) serving the areas of Amsterdam, Maastricht and Doetinchem, respectively. NCR is a national registry of all malignant tumors diagnosed from 1989 onwards in people living in The Netherlands. Completeness, data consistency and the possibility of duplicate records have extensively been checked [24]. Because data from NCR were complete only for the period 1989 to the end of 1996, additional information from the regional cancer registries was used. For 1987 and 1988 completeness of data from these registries varied between 60 and $100 \%$ depending on registry and year. For 1997, data from the three regional cancer registries were $100 \%$ complete and for 1998 , data were $100 \%$ complete for IKL only. Records from the cohort were linked using a method based on the two-stage process developed by Van den Brandt et al. [25]. In total, 251 breast cancer cases were identified. A random sample of controls matched to the cases with the same age (five year intervals), menopausal status, and residence was drawn. We over-sampled our control population by $20 \%$ since the success rate of DNA isolation was expected not to be $100 \%$. Our study population consisted of 251 cases and 300 controls.

\section{Meat consumption}

Meat consumption was recorded at baseline by use of a self-administered questionnaire. Dietary habits were estimated using a short semi-quantitative food frequency method, validated by use of a dietary history method [26]. For women, Spearman's rank correlation 
coefficient for the reproducibility of meat intake as estimated by the questionnaire was $r=0.56$ and 0.40 for relative validity [26]. As the questionnaire was designed to estimate exposure to risk factors of cardiovascular diseases, emphasis was on foods supposed to increase the risk and the questionnaire included separate questions on beef, pork, poultry and fish. Consumption was assessed in six categories: never, less than once per month, $1-3$ times monthly, once per week, $2-4$ times weekly, and more than 4 times per week. In addition, frequency of consumption of five typically Dutch meat snacks was asked in categories of never, less than once weekly, once weekly, 2-6 times per week, and daily. Participants were also asked how many sandwiches with meat filling they used to consume daily.

For each meat item, consumption in gram per day was calculated by the median frequency of the chosen answer category (i.e. for the category ' $2-4$ times weekly' we assumed a consumption of 3/7 times per day), multiplied by its standard portion size. Portion sizes of every meat type were derived from a Dutch national reference book on portion sizes and food coding [27]. Red meat intake in grams per day was calculated by adding up intake of beef and pork. White meat intake in grams per day was calculated by adding up poultry and fish intake. Fresh meat consumption was defined as sum of red and white meat consumption. Processed meat intake was calculated by adding grams of all processed meat items. Finally, total meat consumption comprised fresh plus processed meat intake.

Consumption of vegetables and fruit was calculated in a similar way. Energy intake was estimated using data from the computerized version of the Dutch food composition table in 1993 to estimate portion size [28].

\section{Genotype}

All participants provided a blood sample that was separated into plasma, erythrocytes, and buffy coat and was stored at $-20{ }^{\circ} \mathrm{C}$. Mean storage time until DNA isolation was 11.5 years. For three cases and two controls, no sample could be retrieved.

DNA was isolated from buffy coats of 229 cases and 264 controls (success rate of $91.2 \%$ for cases and $88 \%$ for controls). DNA was diluted to $20 \mathrm{ng} / \mu$ land stored at $4{ }^{\circ} \mathrm{C}$ in deep-well microtiter plates. All genotyping was determined blind to case-control status.

We determined NATl genotype by sequencing two parts of the NAT1 gene (nucleotides 150-650 and 7501150). Nucleotide sequence was determined after purification of the amplified PCR products with Qiaquick PCR Purification Kit (Qiagen, Valencia CA) using the Big-Dye Terminator Cycle Sequencing Kit (Applied
Biosystems, Foster City, CA). Electrophoresis and analysis of DNA sequence reactions were performed with an ABI 310 Genetic Analyzer. Five samples were included in a radioactive hybridization experiment and genotyping results were the same.

NAT2 genotype was determined using single nucleotide polymorphism-specific polymerase chain reaction primers and fluorogenic probes as described by Doll and Hein [29]. Six polymorphic sites were investigated, C282T, T341C, C481T, G590A, A803G, G857A. Since our study population was Caucasian, we did not include G191A [12]. As controls three (homozygote wildtype, heterozygote, homozygote mutant) samples were used in every PCR. Distribution of NAT alleles in our study population was as expected in a Caucasian population (Appendix 1).

Presence or absence of the GSTM1 and GSTT1 gene was assessed by multiplex PCR as described by Chen et al. [30]. Briefly, segments of GSTMI and GSTT1 were amplified along with a segment of human $\beta$-globin. The PCR products were analyzed on agarose gels. A fragment of $215 \mathrm{bp}$ indicated the presence of GSTM1, a fragment of $480 \mathrm{bp}$ indicated the presence of GSTT1 and a fragment of $268 \mathrm{bp}$ indicated the positive internal control $\beta$-globin. Two controls, known to be GSTMI and GSTT1 positive, were used. Presence or absence of GSTM1 and GSTT1 relied on visual inspection of two independent observers. PCR products were inspected twice and concordance within and between the observers was over $95 \%$.

\section{Data analysis}

Relations with breast cancer were analyzed for total meat, processed meat, fresh meat, red meat and white meat. Meat consumption was categorized in three groups of almost equal size. Total meat consumption was categorized in $<75,75-99, \geq 100 \mathrm{~g}$ per day. Processed meat consumption was categorized in $<20,20$ $34, \geq 35 \mathrm{~g}$ per day. Fresh meat consumption was categorized in $<45,45-59, \geq 60 \mathrm{~g}$ per day. Red meat was categorized in $<30,30-44, \geq 45 \mathrm{~g}$ per day. White meat was categorized in $<15,15-29, \geq 30 \mathrm{~g}$ per day.

For $N A T 1$ the corresponding phenotype is not clear. An initial report on increased activity associated with the $N A T 1^{*} 10$ allele [31] could not be supported in subsequent studies [32-35]. However, we maintain the distinction of $N A T 1^{*} 10$ and $N A T 1^{*} 10$ in our studies. Women with at least one $N A T 1^{*} 10$ allele were classified as rapid acetylators. Although only women with at least one $N A T 1^{*} 14 A, N A T 1^{*} 14 B, N A T 1^{*} 15, N A T 1^{*} 17$ and $N A T 1^{*} 22$ should be classified as slow acetylators, this last group is small and therefore all women with no 
$N A T 1 * 10$ allele were classified as one group and referred to as slow acetylators. Slow acetylators were used as reference group.

For $N A T 2$ genotype carriers of a $N A T 2 * 4$, NAT2*12 or $N A T 2 * 13$ allele were classified as rapid and the rest as slow acetylators [36]. Slow acetylators were used as reference group. Absence of GSTM1 or GSTT1 (null genotype) in women was compared to women with those genes present (reference group).

Odds ratio's (OR) and 95\% confidence intervals $(95 \%$ CI) were calculated using logistic regression models. We first analyzed the effect of meat with breast cancer as the dependent variable and meat consumption as the independent variable. Then, the effect of genotype was assessed. To evaluate the combined effect of meat consumption and metabolic genotype, a logistic regression model was used with breast cancer as the dependent variable and a combination of meat consumption and genotype as the independent variable. The joint effect of gene and environment was analyzed using two-by-six tables.

In all models, age, menopausal status, and town were included as covariates because cases and controls were frequency matched. When meat was analyzed, in addition to these covariates energy intake $(\mathrm{kJ}$ per day (continuous)) was also included. These models are referred to as 'base models'. Other factors considered for confounding were smoking (never, $<10,10-19, \geq 20$ pack-years (i.e., number of cigarettes per day divided by 20 and multiplied by years of smoking)), alcohol consumption (never, $<6,6-14, \geq 15$ g per day), BMI (continuous), age at first full term pregnancy (not applicable, $<22,22-25, \geq 26$ ), age at menarche (continuous), and education (primary, technical, secondary and academic), fruit consumption in grams per day (continuous), vegetables consumption in grams per day (continuous) (referred to as full model). We decided to include confounders in the final model if exclusion from the full model changed the risk estimate more than $10 \%$ (referred to as 'final' model). We show results for the full model as well as for the final model. Tests for HardyWeinberg equilibrium were conducted by comparing observed and expected polymorphisms and genotype frequencies using a $\chi^{2}$ test. All analyses were conducted using SPSS 9.0.

\section{Results}

Characteristics of the study population are shown in Table 1. Breast cancer cases reported more packyears of smoking than controls although this was not statistically significant. No significant difference was observed
Table 1. Baseline characteristics of the study population

\begin{tabular}{|c|c|c|}
\hline & $\begin{array}{l}\text { Cases }(\mathrm{n}=229) \\
\text { No }(\% \text { or sd })\end{array}$ & $\begin{array}{l}\text { Controls }(\mathrm{n}=264) \\
\text { No }(\% \text { or sd })\end{array}$ \\
\hline Age (years) & $47.5(8.0)$ & $47.0(9.1)$ \\
\hline Age menopause & $49.2(3.5)$ & $48.9(3.9)$ \\
\hline \multicolumn{3}{|l|}{ Menopausal status } \\
\hline Pre & $127(55.5)$ & $136(51.5)$ \\
\hline Natural menopause & $68(29.7)$ & $85(32.2)$ \\
\hline Artificial menopause & $34(14.8)$ & $43(16.3)$ \\
\hline Age at menarche & $13.4(1.6)$ & $13.4(1.5)$ \\
\hline Nulliparous (yes) & $51(22.3)$ & $60(22.7)$ \\
\hline Age first full term pregnancy & $25.6(4.0)$ & $24.6(3.9)$ \\
\hline Height (cm) & $164.9(6.8)$ & $165.0(6.6)$ \\
\hline Weight (kg) & $68.3(11.3)$ & $69.5(11.9)$ \\
\hline Body Mass Index & $25.1(4.1)$ & $25.5(4.2)$ \\
\hline \multicolumn{3}{|l|}{ Highest level of education } \\
\hline Primary school & $60(26.3)$ & $69(26.2)$ \\
\hline Technical & $106(46.5)$ & $122(46.4)$ \\
\hline Secondary & $31(13.6)$ & $32(12.2)$ \\
\hline Academic & $31(13.6)$ & $40(15.2)$ \\
\hline \multicolumn{3}{|l|}{ Diet } \\
\hline Vegetarian & $23(10)$ & $31(11.7)$ \\
\hline Total meat (g/day) & $88.5(31.8)$ & $89.8(36.7)$ \\
\hline Fresh meat (g/day) & $58.3(25.0)$ & $61.2(29.2)$ \\
\hline Processed meat (g/day) & $30.2(20.8)$ & $28.6(20.1)$ \\
\hline Fresh red meat (g/day) & $36.3(18.1)$ & $34.9(19.6)$ \\
\hline Fresh white meat (g/day) & $22.0(17.2)$ & $26.3(22.8)$ \\
\hline Fruit (g/day) & $111(63)$ & $112(67)$ \\
\hline Vegetables (g/day) & $142(63)$ & $142(84)$ \\
\hline Alcohol (g ethanol/day) & $7.26(9.83)$ & $6.77(9.88)$ \\
\hline Energy intake (kj/day) & $6076(1244)$ & $6175(1488)$ \\
\hline Smoking (packyears) & $12.0(13.5)$ & $10.1(12.8)$ \\
\hline
\end{tabular}

Values are means (sd) or numbers (\%).

between the genotyped and non-genotyped persons (22 cases and 36 controls) with respect to these characteristics (data not shown). For NAT1 and NAT2, all polymorphisms were in $\mathrm{HW}$ equilibrium with $p>0.05$ by $\chi^{2}$ test.

As shown in Table 2, breast cancer risk is not related to total meat consumption, or to any of the meat subcategories, although there is a tendency for increased breast cancer risk for red meat and decreased risk for white meat consumption.

Estimates calculated from the base model did not differ substantially from the estimates obtained from the full model. Therefore, the final model is equal to the base model. Main effects of the metabolic genotypes are shown in Table 3. Only for GSTM1 null genotype, compared to GSTM1 presence, an increased breast cancer risk was observed, $\mathrm{OR}=1.46(95 \% \mathrm{CI}=1.02-$ $2.09)$, which was more pronounced in postmenopausal women $(\mathrm{OR}=1.83(95 \% \mathrm{CI}=1.07-3.13))$ than in premenopausal women $(\mathrm{OR}=1.18(95 \% \mathrm{CI}=0.73-1.94))$. 
Table 2. Meat consumption and breast cancer risk

\begin{tabular}{|c|c|c|c|c|}
\hline & Cases n $(\%)$ & Controls n $(\%)$ & $\mathrm{OR}^{\mathrm{a}}$ & $\mathrm{OR}^{\mathrm{b}}$ \\
\hline \multicolumn{5}{|c|}{ Total meat(g/day) } \\
\hline$<75$ & $75(32)$ & $85(32)$ & 1.00 & 1.00 \\
\hline $75-99$ & $79(32)$ & $79(31)$ & $1.17(0.74-1.87)$ & $1.18(0.75-1.86)$ \\
\hline$\geq 100$ & $74(36)$ & $97(37)$ & $0.94(0.59-1.50)$ & $0.93(0.59-1.48)$ \\
\hline Total & 228 & 261 & & \\
\hline \multicolumn{5}{|c|}{ Processed meat (g/day) } \\
\hline$<20$ & $88(38)$ & $97(37)$ & 1.00 & 1.00 \\
\hline $20-34$ & $64(28)$ & $77(30)$ & $0.95(0.60-1.49)$ & $0.95(0.61-1.49)$ \\
\hline$\geq 35$ & $77(34)$ & $88(33)$ & $1.08(0.60-1.70)$ & $1.05(0.67-1.64)$ \\
\hline Total & 229 & 262 & & \\
\hline \multicolumn{5}{|c|}{ Fresh meat (g/day) } \\
\hline$<45$ & $63(28)$ & $80(31)$ & 1.00 & 1.00 \\
\hline $45-69$ & $92(40)$ & $79(30)$ & $1.61(1.02-2.56)$ & $1.49(0.95-2.35)$ \\
\hline$\geq 70$ & $73(32)$ & $103(39)$ & $0.95(0.59-1.56)$ & $0.93(0.60-1.47)$ \\
\hline Total & 228 & 262 & & \\
\hline \multicolumn{5}{|c|}{ Fresh red meat (g/day) } \\
\hline$<30$ & $70(30)$ & $94(36)$ & 1.00 & 1.00 \\
\hline $30-44$ & $77(34)$ & $81(31)$ & $1.30(0.82-2.06)$ & $1.31(0.83-2.05)$ \\
\hline$\geq 45$ & $82(36)$ & $88(33)$ & $1.32(0.84-2.08)$ & $1.30(0.83-2.02)$ \\
\hline Total & 229 & 263 & & \\
\hline \multicolumn{5}{|c|}{ Fresh white meat (g/day) } \\
\hline$<15$ & $102(45)$ & $100(38)$ & 1.00 & 1.00 \\
\hline $15-29$ & $55(24)$ & $68(26)$ & $0.80(0.50-1.27)$ & $0.83(0.53-1.31)$ \\
\hline$\geq 30$ & $71(31)$ & $94(36)$ & $0.75(0.49-1.14)$ & $0.76(0.50-1.15)$ \\
\hline Total & 228 & 262 & & \\
\hline
\end{tabular}

a OR from the full model: in addition to base model (adjusted for age, menopausal status, town, energy intake) adjusted for smoking, alcohol, age at menarche and BMI.

b Final Model: adjusted for age, menopausal status, town, and energy intake (is equivalent to the base model).

Table 3. NAT1, NAT2, GSTM1, GSTT1 genotypes and breast cancer risk

\begin{tabular}{|c|c|c|c|c|}
\hline Genotypes & Cases n $(\%)$ & Controls n $(\%)$ & $\mathrm{OR}^{\mathrm{a}}$ & $\mathrm{OR}^{\mathrm{b}}$ \\
\hline \multicolumn{5}{|l|}{ NAT1 genotype } \\
\hline non $N A T 1 * 10$ & $151(66)$ & $176(67)$ & 1.00 & 1.00 \\
\hline$N A T 1 * 10$ & $77(34)$ & $88(33)$ & $1.07(0.73-0.57)$ & $1.03(0.70-1.50)$ \\
\hline Total & $228^{\mathrm{c}}$ & 264 & & \\
\hline \multicolumn{5}{|l|}{ NAT2 genotype } \\
\hline Slow & $143(62)$ & $158(60)$ & 1.00 & 1.00 \\
\hline Rapid & $86(38)$ & $106(40)$ & $0.88(0.61-1.28)$ & $0.88(0.61-1.28)$ \\
\hline Total & 229 & 264 & & \\
\hline \multicolumn{5}{|l|}{ GSTM1 } \\
\hline Present & $96(42)$ & $134(51)$ & 1.00 & 1.00 \\
\hline Absent (Null genotype) & $133(58)$ & $129(49)$ & $1.52(1.06-2.19)$ & $1.46(1.02-2.09)$ \\
\hline Total & 229 & $263^{\mathrm{c}}$ & & \\
\hline \multicolumn{5}{|l|}{ GSTT1 } \\
\hline Present & $193(84)$ & $213(81)$ & 1.00 & 1.00 \\
\hline Absent (Null genotype) & $36(16)$ & $50(19)$ & $0.77(0.48-1.24)$ & $0.78(0.49-1.26)$ \\
\hline Total & 229 & $263^{\mathrm{c}}$ & & \\
\hline
\end{tabular}

a OR from the full model: in addition to base model (adjusted for age, town and menopausal status), adjusted for smoking, alcohol, age at menarche and BMI.

b Final model: adjusted for age, town, and menopausal status (is equivalent to the base model).

c For one sample it was not possible to determine NAT1genotype and for another it was not possible to determine GSTM1 and GSTT1 presence or absence. 
Total meat consumption in combination with rapid NAT1 or NAT2 genotype or in absence of GSTT1 did not influence breast cancer risk. A joint effect of meat subcategories (i.e., processed, fresh, red and white meat) and one of those genotypes was also not observed (data not shown).

When stratifying women according to combined 'GSTM1 genotype-meat consumption' categories (Table 4), breast cancer risk is only slightly related to consumption of red meat in women with GSTMI present. The risks for intermediate and high amount of consumption compared to a low amount of consumption are: $\quad \mathrm{OR}=1.49 \quad(95 \% \quad \mathrm{CI}=0.76-2.94) \quad$ and $\mathrm{OR}=1.75(95 \% \mathrm{CI}=0.91-3.70)$ respectively. The effect of red meat consumption in women with GSTM1 null genotype is also small, or absent; for intermediate and high amount of consumption OR $=1.18(=2.28 / 1.94)$ and $1.02(=1.98 / 1.94)$, respectively, when compared to low consumption in women with GSTM1 null genotype. These risks are not statistically significant, and do not consistently show to be related in a dose dependent manner to amount of red meat consumption. Test for interaction is not significant, so there is no modifying effect of GSTM1 on the relation between red meat consumption and breast cancer risk.

Statistically significant increased risks are observed for women with combined 'GSTMI null genotype and any amount of red meat consumption' compared to women with 'GSTM1 present and low consumption' (Table 4). These effects are attributable to the main effect of GSTM1 null genotype that increases breast cancer risk irrespective of meat consumption. For postmenopausal women effects of red meat consumption are slightly stronger, although still not statistically

Table 4. GSTM1 genotype and meat consumption and breast cancer risk

\begin{tabular}{|c|c|c|c|c|c|}
\hline$G S T M 1$ & Meat & Cases n (\%) & Controls n $(\%)$ & $\mathrm{OR}^{\mathrm{a}}$ & $\mathrm{OR}^{\mathrm{b}}$ \\
\hline & \multicolumn{5}{|c|}{ Total meat (g/day) } \\
\hline Present & $<75$ & $28(12)$ & 45 (17) & 1.00 & 1.00 \\
\hline Present & $75-100$ & 37 (16) & $38(14)$ & $1.62(0.82-3.18)$ & $1.62(0.83-3.14)$ \\
\hline Present & $\geq 100$ & $30(13)$ & $51(20)$ & $1.06(0.54-2.10)$ & $1.02(0.52-2.00)$ \\
\hline Null & $<75$ & $47(21)$ & $39(15)$ & $2.12(1.10-4.06)$ & $1.98(1.04-3.75)$ \\
\hline Null & $75-100$ & $42(18)$ & $41(16)$ & $1.85(0.92-3.61)$ & $1.74(0.90-3.35)$ \\
\hline Null & $\geq 100$ & $44(20)$ & $46(18)$ & $1.75(0.90-3.40)$ & $1.66(0.87-3.17)$ \\
\hline \multirow[t]{2}{*}{ Total } & & 228 & 260 & & \\
\hline & \multicolumn{5}{|c|}{ Fresh meat (g/day) } \\
\hline Present & $<45$ & $23(10)$ & 43 (16) & 1.00 & 1.00 \\
\hline Present & $45-69$ & $38(17)$ & $36(14)$ & $2.07(1.03-4.16)$ & $1.96(0.99-3.88)$ \\
\hline Present & $\geq 70$ & $34(15)$ & $55(21)$ & $1.26(0.64-2.51)$ & $1.21(0.62-2.36)$ \\
\hline Null & $<45$ & $40(17)$ & $36(14)$ & $2.23(1.11-4.49)$ & $2.11(1.07-4.18)$ \\
\hline Null & $45-69$ & $54(24)$ & 43 (16) & $2.80(1.43-5.47)$ & $2.43(1.27-4.68)$ \\
\hline Null & $\geq 70$ & $39(17)$ & 48 (19) & $1.64(0.83-3.24)$ & $1.56(0.80-3.05)$ \\
\hline \multirow[t]{2}{*}{ Total } & & 228 & 262 & & \\
\hline & \multicolumn{5}{|c|}{ Red meat (g/day) } \\
\hline Present & $<30$ & $25(11)$ & 48 (19) & 1.00 & 1.00 \\
\hline Present & $30-45$ & $35(15)$ & $41(16)$ & $1.49(0.75-2.98)$ & $1.49(0.76-2.94)$ \\
\hline Present & $\geq 45$ & $40(17)$ & $45(17)$ & $1.80(0.92-3.51)$ & $1.75(0.91-3.70)$ \\
\hline Null & $<30$ & 45 (19) & 45 (17) & $2.04(1.06-3.94)$ & $1.94(1.02-3.68)$ \\
\hline Null & $30-45$ & $46(20)$ & $40(15)$ & $2.37(1.22-4.60)$ & $2.28(1.19-4.38)$ \\
\hline Null & $\geq 45$ & $42(18)$ & $43(16)$ & $2.11(1.08-4.14)$ & $1.98(1.03-3.81)$ \\
\hline \multirow[t]{2}{*}{ Total } & & 229 & 262 & & \\
\hline & \multicolumn{5}{|c|}{ White meat (g/day) } \\
\hline Present & $<30$ & 44 (19) & $51(20)$ & 1.00 & 1.00 \\
\hline Present & $30-45$ & $20(9)$ & $38(14)$ & $0.62(0.31-1.24)$ & $0.65(0.33-1.30)$ \\
\hline Present & $\geq 45$ & $31(14)$ & 45 (17) & $0.85(0.45-1.59)$ & $0.84(0.45-1.57)$ \\
\hline Null & $<30$ & $58(25)$ & 49 (19) & $1.51(0.85-2.68)$ & $1.44(0.82-2.52)$ \\
\hline Null & $30-45$ & $35(15)$ & $29(11)$ & $1.55(0.80-2.97)$ & $1.50(0.79-2.85)$ \\
\hline Null & $\geq 45$ & $40(18)$ & 49 (19) & $1.00(0.55-1.82)$ & $0.98(0.55-1.76)$ \\
\hline Total & & 228 & 261 & & \\
\hline
\end{tabular}

a Odds ratio from the full model: in addition to base model (adjusted for age, town, menopausal status, and energy intake) adjusted for smoking, alcohol, age at menarche and BMI.

b Final model: adjusted for age, town, menopausal status, and energy intake (is equivalent to the base model). 
significant (data not shown): $\mathrm{OR}=1.79(95 \% \mathrm{CI}=0.92-$ $3.50)$ and 1.46 (95\% CI: 0.76-2.82) for intermediate and high compared to low red meat consumption respectively. The effect of red meat is statistically significant and strong in women with $G S T M 1$ present $(\mathrm{OR}=4.46$ and 4.97 (for intermediate and high consumption versus low, respectively). But in women with GSTM1 null genotype, red meat consumption shows no or even a reversed (preventive) effect $(\mathrm{OR}=0.97$ and 0.64 for intermediate and high red meat consumption versus low, respectively). Due to the different slopes, the test for interaction is significant, although the number of breast cancer cases is small (i.e., 101 cases).

\section{Discussion}

Risk of breast cancer is statistically significant increased in women with GSTM1 null genotype. Red meat consumption - if any - only slightly increases breast cancer risk, both in women with GSTM1 present or absent. Amount of red meat consumption does not influence the effect in a dose dependent way; and there is no modifying effect of GSTMI genetic make up on the relation between meat and breast cancer. For other metabolizing genes (NAT1, NAT2, and GSTT1) there is no effect on breast cancer risk and we did not find any modifying effect of these genes on the relation between meat and breast cancer risk.

A nested case control study has as a major advantage over a conventional case control study that meat consumption data are collected prior to disease occurrence thus excluding recall bias of consumption due to the presence of the disease. Exclusion of cases occurring in the first year of follow-up did not change the results, which indeed indicates that information on meat consumption was probably not biased by presence of (latent) disease.

Furthermore, the exclusion of early diagnosed cases to minimize potential recall bias, will at the same time result in an analysis with complete case ascertainment for remaining study persons. Due to the initiation of the cancer registration in the late 1980's in the Netherlands registration was still incomplete in the first year of the follow-up of cohort participants (1987-1988). In addition, for the years 1997 and 1998 identification of cases was based on regional cancer registries only. However, this has caused only few missed cases and was estimated to be less than $0.3 \%$ [24]. Since study results were the same when analyses were done for cases occurring after the first year of study entry, non-complete case ascertainment was not considered to have a meaningful influence on our findings, except somewhat reducing our power.

Since genotyping was done blinded to case or control status any misclassification is therefore random and will, if anything, dilute the results.

The cohort study was designed to estimate exposure to risk factors of cardiovascular diseases; therefore information on familial breast cancer risk was not included in our study. Other known breast cancer risk factors showed risks as expected, i.e., each delayed year of age at first full term pregnancy increased risk with 7\% $(\mathrm{OR}=1.07(95 \% \mathrm{CI}=1.02-1.13))$.

Main effects of total meat consumption on breast cancer risk were not observed in the present study. This is consistent with a pooled analysis of cohort studies [1]. Due to absence of data, our analysis did not take into account 'well doneness' of meat. Mutagens and carcinogens are formed during cooking at high temperature [37]. To be more specific, fried, barbecued or flamebroiled meats have a higher mutagenic activity than stewed, baked, boiled or steamed meat [2]. Fried meat was associated with breast cancer in a case-control study from Uruguay [3]. In addition these authors found a significant positive effect for the highest quartile of estimated HA exposure. Zheng et al. [5] found that consumption of well-done meat might play an important role in breast cancer risk. It is known that in The Netherlands, the preparation of red meat is more often fried than barbecued.

We did not observe significantly elevated breast cancer risks for women who possess a NAT1, NAT2 or GSTT1 hypothesized high-risk genotype alone or combined with any category of meat consumption. In general there have been no consistent results reported on acetylator genotype, meat consumption and breast cancer risk. No combined effect of meat and NAT2 acetylator genotype was found in two studies [15, 19], but one study showed that among women with rapid NAT2 genotype, consumption of well-done meat was associated with a nearly eight-fold elevated breast cancer risk compared with those consuming rare or mediumdone meat [14].

We observed an increased breast cancer risk for women with GSTMI null genotype, independent of the amount of red meat intake. This risk was even higher in postmenopausal women. This might be a reflection of cumulative life time exposure to carcinogens, which is for postmenopausal women higher than for premenopausal women.

Another recent meta-analysis concluded that meat intake does increase breast cancer risk (meat intake in highest level compared to lowest $(\mathrm{RR}=1.17(95 \%$ $\mathrm{CI}=1.06-1.29)))$ [38]. In accordance with this result, we 
observe for red meat consumption slightly increases in breast cancer risk, both in women with and without GSTM1 null genotype. Absence of a red meat dose response relation may suggest that potential procarcinogens in red meat are detoxified by other enzymes, or that other carcinogens, not from red meat, play a role in breast cancer development. There is no modifying effect of GSTM1 on the relation between meat and breast cancer. We observed strong and statistically significant effects of red meat consumption only in postmenopausal women who have GSTM1 present $(\mathrm{OR}>4)$. But the effect of red meat consumption was absent or even reversed in women with GSTM1 null genotype (test for interaction $p<0.04)$. This is biologically hard to understand and in combination with the small number of cases included in this sub-analysis $(n=101)$, we should consider a false positive result as a clarification too. At least, this result should be replicated in other studies before concluding that red meat consumption may increase breast cancer risk in postmenopausal women.

In conclusion, this study shows an effect of GSTM1 null genotype: women who have a genetically determined defect in their detoxification process of carcinogens are at increased risk for breast cancer. We found slightly increased risks for red meat consumption, but not statistically significant. We were unable to show modifying effects of any of the metabolizing genes NAT1, NAT2, GSTT1 or GSTM1 on the relation between red meat consumption and breast cancer risk.

\section{Acknowledgements}

The data for this study originated from The Monitoring Project on Cardiovascular Disease Factors, financially supported by the Ministry of Public Health, Welfare and Sports of The Netherlands.

G.L. Obermann-de Boer is kindly acknowledged for coordinating the study and the epidemiologists and field-workers of the Municipal Health Services in Amsterdam, Doetinchem, and Maastricht for their contribution to the data collection. We are thankful to L.J. Schouten (NCR/IKL), O. Visser (IKA), and J. van Dijck (IKO), for their support in the linkage with the cancer registries. We further wish to thank the following persons affiliated to the Netherlands Institute of Public Health and the Environment in Bilthoven, The Netherlands: A. Blokstra, E. den Hoedt, A. van Kessel, and P. Steinberger for data management and retrieval; A.J.M. van Loon and M.C.J.F. Jansen for their help with retrieval of data from the cancer registries and data management; B. Hoebee, E.M. van Schothorst, and
P. van Impelen for help with retrieval of samples and DNA isolation. We thank B. Slothouber from Julius Center for Health Sciences and Primary Care for help with genotyping the samples.

Acknowledgement of financial support: The studies outlined in this manuscript were supported in part by United States Public Health Service grant CA34627 from the National Cancer Institute, from the Dutch Cancer Society (UU 98-1707), and from Sineke ten Horn fund and from the travel fund of the Dutch Cancer Society.

\section{Appendix 1.}

Frequencies of $N A T 1$ and $N A T 2$ alleles.

\begin{tabular}{|c|c|c|c|c|}
\hline \multirow[t]{2}{*}{ Alleles } & \multicolumn{2}{|c|}{ Cases } & \multicolumn{2}{|c|}{ Controls } \\
\hline & $\mathrm{n}$ & $\%$ & $\mathrm{n}$ & $\%$ \\
\hline \multicolumn{5}{|l|}{$N A T 1$ alleles } \\
\hline$N A T 1^{*} 3$ & 12 & 2.6 & 13 & 2.5 \\
\hline$N A T 1^{*} 4$ & 334 & 73.2 & 394 & 74.6 \\
\hline$N A T 1^{*} 10$ & 87 & 19.1 & 97 & 18.4 \\
\hline$N A T 1^{*} 11$ & 8 & 1.8 & 8 & 1.5 \\
\hline$N A T 1^{*} 14 A$ & 9 & 2.0 & 8 & 1.5 \\
\hline$N A T 1^{*} 14 B$ & & & 1 & 0.2 \\
\hline$N A T 1^{*} 15$ & 1 & 0.2 & 3 & 0.6 \\
\hline$N A T 1 * 17$ & 2 & 0.4 & 3 & 0.6 \\
\hline$N A T 1^{*} 22$ & 3 & 0.7 & 1 & 0.2 \\
\hline Total & 456 & & 528 & \\
\hline \multicolumn{5}{|l|}{$N A T 2$ alleles } \\
\hline$N A T 2 * 4$ & 98 & 21.3 & 112 & 21.3 \\
\hline$N A T 2^{*} 5 A$ & 10 & 2.2 & 14 & 2.7 \\
\hline$N A T 2 * 5 B$ & 196 & 42.8 & 216 & 41.1 \\
\hline$N A T 2 * 5 C$ & 9 & 2.0 & 4 & 0.8 \\
\hline$N A T 2^{*} 6 A$ & 131 & 28.7 & 154 & 29.3 \\
\hline$N A T 2 * 6 B$ & 1 & 0.2 & 0 & \\
\hline$N A T 2^{*} 6 C$ & 1 & 0.2 & 1 & 0.2 \\
\hline$N A T 2 * 7 B$ & 11 & 2.4 & 17 & 3.2 \\
\hline$N A T 2 * 12 A$ & 1 & 0.2 & 5 & 0.9 \\
\hline$N A T 2 * 12 B$ & 0 & & 2 & 0.4 \\
\hline$N A T 2 * 13$ & 0 & & 1 & 0.2 \\
\hline Total & 458 & & 526 & \\
\hline
\end{tabular}

\section{References}

1. Missmer SA, Smith-Warner SA, Spiegelman D, et al. (2002) Meat and dairy food consumption and breast cancer: a pooled analysis of cohort studies. Int J Epidemiol 31: 78-85.

2. Layton DW, Bogen KT, Knize MG, Hatch FT, Johnson VM, Felton JS (1995) Cancer risk of heterocyclic amines in cooked foods: an analysis and implications for research. Carcinogenesis 16: 39-52.

3. De Stefani E, Ronco A, Mendilaharsu M, Guidobono M, DeneoPellegrini H (1997) Meat intake, heterocyclic amines, and risk of breast cancer: a case-control study in Uruguay. Cancer Epidemiol Biomarkers Prev 6: 573-581. 
4. Knekt P, Steineck G, Jarvinen R, Hakulinen T, Aromaa A (1994) Intake of fried meat and risk of cancer: a follow-up study in Finland. Int $J$ Cancer 59: 756-760.

5. Zheng W, Gustafson DR, Sinha R, et al. (1998) Well-done meat intake and the risk of breast cancer. J Natl Cancer Inst 90: 1724 1729.

6. Iscovich JM, Iscovich RB, Howe G, Shiboski S, Kaldor JM (1989) A case-control study of diet and breast cancer in Argentina. Int $J$ Cancer 44: 770-776.

7. Nagao M, Ushijima T, Wakabayashi K, et al. (1994) Dietary carcinogens and mammary carcinogenesis. Induction of rat mammary carcinomas by administration of heterocyclic amines in cooked foods. Cancer 74: 1063-1069.

8. Williams JA, Phillips DH (2000) Mammary expression of xenobiotic metabolizing enzymes and their potential role in breast cancer. Cancer Res 60: 4667-4677.

9. Lightfoot TJ, Coxhead JM, Cupid BC, Nicholson S, Garner RC (2000) Analysis of DNA adducts by accelerator mass spectrometry in human breast tissue after administration of 2-amino-1-methyl-6phenylimidazo[4,5-b]pyridine and benzo[a]pyrene. Mutat Res 472: 119-127.

10. Gorlewska-Roberts K, Green B, Fares M, Ambrosone CB, Kadlubar FF (2002) Carcinogen-DNA adducts in human breast epithelial cells. Environ Mol Mutagen 39: 184-192.

11. Hein DW, Ferguson RJ, Doll MA, Rustan TD, Gray K (1994) Molecular genetics of human polymorphic $N$-acetyltransferase: enzymatic analysis of 15 recombinant wild-type, mutant, and chimeric NAT2 allozymes. Hum Mol Genet 3: 729-734.

12. Hein DW, Doll MA, Fretland AJ, et al. (2000) Molecular genetics and epidemiology of the NAT1 and NAT2 acetylation polymorphisms. Cancer Epidemiol Biomarkers Prev 9: 29-42.

13. Krajinovic M, Ghadirian P, Richer C, et al. (2001) Genetic susceptibility to breast cancer in French-Canadians: role of carcinogen-metabolizing enzymes and gene-environment interactions. Int $J$ Cancer 92: 220-225.

14. Deitz AC, Zheng W, Leff MA, et al. (2000) N-Acetyltransferase-2 genetic polymorphism, well-done meat intake, and breast cancer risk among postmenopausal women. Cancer Epidemiol Biomarkers Prev 9: 905-910.

15. Gertig DM, Hankinson SE, Hough H, et al. (1999) $N$-acetyl transferase 2 genotypes, meat intake and breast cancer risk. Int $J$ Cancer 80: 13-17.

16. Huang CS, Chern HD, Shen CY, Hsu SM, Chang KJ (1999) Association between $N$-acetyltransferase 2 (NAT2) genetic polymorphism and development of breast cancer in post-menopausal Chinese women in Taiwan, an area of great increase in breast cancer incidence. Int J Cancer 82: 175-179.

17. Delfino RJ, Sinha R, Smith C, et al. (2000) Breast cancer, heterocyclic aromatic amines from meat and $N$-acetyltransferase 2 genotype. Carcinogenesis 21: 607-615.

18. Zheng W, Deitz AC, Campbell DR, et al. (1999) $N$-acetyltransferase 1 genetic polymorphism, cigarette smoking, well-done meat intake, and breast cancer risk. Cancer Epidemiol Biomarkers Prev 8: $233-239$.

19. Ambrosone CB, Freudenheim JL, Sinha R, et al. (1998) Breast cancer risk, meat consumption and $N$-acetyltransferase (NAT2) genetic polymorphisms. Int $J$ Cancer 75: 825-830.

20. Rundle A, Tang D, Zhou J, Cho S, Perera F (2000) The association between glutathione S-transferase M1 genotype and polycyclic aromatic hydrocarbon-DNA adducts in breast tissue. Cancer Epidemiol Biomarkers Prev 9: 1079-1085.
21. Rundle A, Tang D, Hibshoosh H, et al. (2002) Molecular epidemiologic studies of polycyclic aromatic hydrocarbon-DNA adducts and breast cancer. Environ Mol Mutagen 39: 201207.

22. Seidegard J, Vorachek WR, Pero RW, Pearson WR (1988) Hereditary differences in the expression of the human glutathione transferase active on trans-stilbene oxide are due to a gene deletion. Proc Natl Acad Sci USA 85: 7293-7297.

23. Verschuren WMM, van Leer EM, Blokstra A, et al. (1993) Cardiovascular disease risk factors in The Netherlands. Neth $J$ Cardiol 6: 205-210.

24. de Winter GA, Coebergh JWW, van Leeuwen FE, Schouten LJ (1990) Incidence of cancer in The Netherlands 1989. First report of the Netherlands Cancer Registry. Utrecht: Hoonte-Holland b.v.

25. Van den Brandt PA, Schouten LJ, Goldbohm RA, Dorant E, Hunen PM (1990) Development of a record linkage protocol for use in the Dutch Cancer Registry for Epidemiological Research. Int J Epidemiol 19: 553-558.

26. Bloemberg BPM (1993) On the effect of measurement error in nutritional epidemiology using dietary history and food frequency methodology. Thesis, University of Leiden.

27. Donders-Engelen MR, Heijden van der L, Hulshof KFAM (1997) Maten, gewichten en codenummers 1997. Wageningen, Landbouwuniversiteit, Zeist, TNO.

28. NEVO. Nederlands Voedingsstoffenbestand 1993 (1993) Den Haag, The Netherlands.

29. Doll MA, Hein DW (2001) Comprehensive Human NAT2 Genotype Method Using Single Nucleotide Polymorphism-Specific Polymerase Chain Reaction Primers and Fluorogenic Probes. Anal Biochem 288: 106-108.

30. Chen CL, Liu Q, Relling MV (1996) Simultaneous characterization of glutathione $S$-transferase M1 and T1 polymorphisms by polymerase chain reaction in American whites and blacks. Pharmacogenetics 6: 187-191.

31. Bell DA, Badawi AF, Lang NP, Ilett KF, Kadlubar FF, Hirvonen A (1995) Polymorphism in the $N$-acetyltransferase 1 (NAT1) polyadenylation signal: association of NAT1*10 allele with higher $\mathrm{N}$-acetylation activity in bladder and colon tissue. Cancer Res $\mathbf{5 5}$ : 5226-5229.

32. Bruhn C, Brockmoller J, Cascorbi I, Roots I, Borchert HH (1999) Correlation between genotype and phenotype of the human arylamine $N$-acetyltransferase type 1 (NAT1). Biochem Pharmacol 58: 1759-1764.

33. Payton MA, Sim E (1998) Genotyping human arylamine $N$ acetyltransferase type 1 (NAT1): the identification of two novel allelic variants. Biochem Pharmacol 55: 361-366.

34. Butcher NJ, Ilett KF, Minchin RF (1998) Functional polymorphism of the human arylamine $N$-acetyltransferase type 1 gene caused by C190T and G560A mutations. Pharmacogenetics 8: 6772.

35. Smelt VA, Mardon HJ, Sim E (1998) Placental expression of arylamine $N$-acetyltransferases: evidence for linkage disequilibrium between NAT $1 * 10$ and NAT2*4 alleles of the two human arylamine $N$-acetyltransferase loci NAT1 and NAT2. Pharmacol Toxicol 83: 149-157.

36. www.louisville.edu/medschool/pharmacology/NAT.html.

37. Egan KM, Giovannucci E (1998) Dietary mutagens and the risk of breast cancer. $J$ Natl Cancer Inst 90: 1687-1689.

38. Boyd NF, Stone J, Vogt KN, Connelly BS, Martin LJ, Minkin S (2003) Dietary fat and breast cancer risk revisited: a meta-analysis of the published literature. Br J Cancer 89: 1672-1685. 